AIAA-2001-3862

\title{
ODC-FREE SOLVENT IMPLEMENTATION FOR PHENOLICS CLEANING
}

\author{
Laura Wurth, Lydia Biegert, and DT Lamont \\ Thiokol Corporation of Cordant Technologies Inc., Brigham City, UT 84302-0707
}

\begin{abstract}
During phenolic liner manufacture, resin-impregnated (pre-preg) bias tape of silica, glass, or carbon cloth is tape-wrapped, cured, machined, and then wiped with 1,1,1 tri-chloroethane (TCA) to remove contaminants that may have been introduced during machining and handling. Following the TCA wipe, the machined surface is given a resin wet-coat and over-wrapped with more prepreg and cured. A TCA replacement solvent for these wiping operations must effectively remove both surface contaminants, and sub-surface oils and greases while not compromising the integrity of this interface.

Selection of a TCA replacement solvent for phenolic over-wrap interface cleaning began with sub-scale compatibility tests with cured phenolics. Additional compatibility tests included assessment of solvent retention in machined phenolic surfaces. Results from these tests showed that, while the candidate solvent did not degrade the cured phenolics, it was retained in higher concentrations than TCA in phenolic surfaces. This effect was most pronounced with glass and silica cloth phenolics with steep ply angles relative to the wiped surfaces.

To determine the effects of retained solvent on the strength of the over-wrap interface, it was necessary to perform bond tests using different combinations of phenolics and ply angles. At the time, no accepted methods existed for evaluation of the phenolic overwrap interface, so, a new sub-scale test was needed for evaluation of the phenolic over-wrap interface. Initial sample design consisted of a button-to-button tensile adhesion configuration with a cored disk of phenolic containing an over-wrap interface secondarily bonded to tensile adhesion buttons. A steep ply orientation on both wiped and over-wrap phenolics provided a worstcase condition for contamination and solvent uptake. Results for non-contaminated test samples showed no degradation of over-wrap interface strength with use of the candidate solvent for interface final wipe. Results for contaminated test samples showed generally
\end{abstract}

acceptable performance for the candidate solvent, however, results for selected phenolic/contaminant combinations were confounded by problems with cleanliness inspection procedures and sample design. A re-test of these phenolic/contaminant combinations using modified sample design and inspection procedures is in work.

\section{INTRODUCTION}

Phenolic materials are used to make ablative liners for use in nozzles of both solid and liquid rocket motors. In the case of solid fuel motors, the liners may contain two layers: for example, a carbon cloth phenolic (CCP) layer on the flame surface, and a glass (GCP) or silica cloth (SCP) phenolic adjacent to the metal housing. During motor operation, the carbon cloth phenolic functions as a high temperature ablative, while the glass or silica cloth phenolic serves to insulate the underlying metal housing and provides structural support.

Phenolic nozzle liners are fabricated using a tape-wrap process in which phenolic impregnated cloth is wrapped onto a mandrel using directed hot air to soften the resin, allowing layers to adhere to one another. Following the tape wrap, the phenolic layer is autoclave or hydroclave cured and then machined. To form the second phenolic layer, the process is repeated with the new prepreg being applied to the machined surface of the initial cured layer, following application of a thin, "wet-coat" layer of uncured resin. This second phenolic layer is referred to as the over-wrap layer. A wide variety of ply angles can be produced on both layers through use of starting ramps during the tape wrap operation.

Solvent hand-wiping is used heavily throughout the phenolic liner fabrication process for operations such as mandrel cleaning prior to start of tape-wrap, mandrel seal surface cleaning prior to vacuum-bag application, final wipe of machined phenolic surfaces prior to overwrap, and removal of incidental contamination from machined phenolic surfaces For some nozzle types, the majority of these solvent hand-wipe operations are currently conducted using 1,1,1 tri-chloroethane (TCA).

(C) 2001 ATK Thiokol Propulsion Corp. Published by the American Institute of Aeronautics and Astronautics, Inc. with permission. 
Due to the large quantities of TCA needed to perform many of these cleaning operations, phenolic fabrication consumes approximately $150 \mathrm{lb}$ of TCA per nozzle, or around $4 \%$ of annual plant-wide, use at ATK, Thiokol Propulsion.

Use of TCA is currently prohibited in the United States because of its effect on stratospheric ozone. Thiokol has been permitted to continue use of TCA under an EPA "essential use" waiver. As part of the essential use waiver agreement, Thiokol is obligated to make all efforts to eliminate TCA use as quickly as possible. Selection and qualification of a TCA replacement solvent for phenolic fabrication operations represents part of that effort.

As a result of preliminary cleaning, compatibility, safety, and operator acceptance testing, Plus 4 (PL4), manufactured by Petroferm, was chosen as the topchoice candidate ODC-free solvent to replace TCA for phenolic fabrication operations. The next step in the qualification process included evaluation of PL4's effects on the strength and integrity of phenolic overwrap interfaces. The remainder of this paper will discuss the compatibility tests and sub-scale test effort used to evaluate PLA's suitability for contamination removal and final wipe of phenolic over-wrap interfaces in phenolic liners.

\section{COMPATIBILITY TESTING}

One of the first tasks involved in qualifying a solvent for use on a material is ensuring that the solvent will not react or otherwise adversely affect the material it is being used to wipe or clean. The preliminary compatibility tests used to select PL4 included several assessments of PL4's compatibility with cured phenolic materials. These tests included the following:

- Measurement of weight, hardness, and volume change of CCP, GCP, and SCP coupons soaked in PLA for periods of 22 and 72 hours.

- Uniaxial tensile testing of CCP, GCP, and SCP dogbone samples following immersion in PL4 for 15 minutes.

- Differential Scanning Calorimetry (DSC) of cured CCP, GCP, and SCP coupons immersed in PL4. Testing was conducted using a temperature range of 25 to $310^{\circ} \mathrm{C}$ using a heating rate of $20^{\circ} \mathrm{C} / \mathrm{min}$.

Results of these tests showed no significant differences between phenolic samples treated with PL4 and similar samples treated with TCA. Based on these results, it was concluded that PL4 does not react with or otherwise degrade cured CCP, GCP, or SCP.

\section{POROSITY ISSUES}

Knowing that PL4 did not degrade cured phenolic substrates, the next step toward evaluating its suitability for the phenolic over-wrap was an evaluation of PL4's intrusion and retention in cured phenolics. Unlike metal substrates, cured phenolics are porous, with the porosity oriented parallel to the fiber direction. In silica and glass cloth phenolics, porosity exists in the form of micro-cracks at the fiber/matrix interface. In rayonbased carbon cloth phenolics, the porosity exists as crenulations in the carbon fibers, formed during carbonization. Due to the orientation of this porosity, phenolics whose fabric plies form a steep angle with respect to the wiped surface tend to absorb solvents and contaminants to greater depths and retain them for longer durations than comparable phenolics with plies oriented at shallow angles with respect to the wiped surface.

Solvents retained in the pore structure of cured phenolics can migrate into the uncured wet-coat and over-wrap during over-wrap and cure, potentially resulting in voids, unbonds, or improper cure of the over-wrap phenolics. TCA does not present these problems since its high vapor pressure $(\approx 100$ torr at room temperature) allows it to flash off completely prior to wet-coat application. PLA, with its relatively low vapor pressure $(\approx 10$ torr at room temperature) does not flash off quickly, and, therefore, has more potential for intrusion and retention in cured phenolic surfaces, especially those with high ply angles relative to the wiped surface.

PL4's tendency for absorption and retention was evaluated using microtome-gas chromatography mass spectroscopy (GCMS). This technique involved using an automated microtome to remove small slices from a solvent-cleaned surface, and then analyzing those slices via GCMS to determine the quantity of solvent present in the slice. By repetitive microtoming and analyzing, it was possible to construct a depth profile of residual solvent in the substrate. In these tests, coupons of solvent-wiped CCP, GCP, and SCP in both $0^{\circ}$ (plies parallel to the wiped surface) and $90^{\circ}$ (plies perpendicular to the wiped surface) configurations were analyzed via microtome GCMS to determine the extent of solvent intrusion after varying dry times. Results are reported in Figures 1-3 as solvent concentration at depth for each unique combination of material, ply angle, and drying time. The designation "ND" in the tables indicates that the solvent was not detected. 
Figure 1: Solvent Depth Profiles - CCP

CCP - 90 degrees

\begin{tabular}{|c|c|c|c|}
\hline Solvent & $\begin{array}{c}\text { Time from } \\
\text { Wipe }(\mathrm{min})\end{array}$ & $\begin{array}{c}\text { Depth } \\
(\mathrm{mm})\end{array}$ & $\begin{array}{c}\text { Conc. } \\
(\mu \mathrm{g} / \mathrm{g})\end{array}$ \\
\hline TCA & 15 & .15 & 129 \\
\hline & & .3 & 62.7 \\
\hline & & .4 & 24.8 \\
\hline & 30 & .15 & 192 \\
\hline & & .3 & 61.0 \\
\hline & & .4 & 22.8 \\
\hline & 60 & .15 & 28.7 \\
\hline & & .25 & 10.4 \\
\hline PL4 & & .35 & 4.4 \\
\hline & 15 & .15 & ND \\
\hline & & .25 & ND \\
\hline & 30 & .35 & ND \\
\hline & & .15 & ND \\
\hline & & .35 & ND \\
\hline & 60 & .15 & ND \\
\hline & & .25 & ND \\
\hline & & .35 & ND \\
\hline
\end{tabular}

$\mathrm{CCP}-0$ degrees

\begin{tabular}{|c|c|c|c|}
\hline Solvent & $\begin{array}{c}\text { Time from } \\
\text { Wipe (min) }\end{array}$ & $\begin{array}{c}\text { Depth } \\
(\mathrm{mm})\end{array}$ & $\begin{array}{c}\text { Conc. } \\
(\mu \mathrm{g} / \mathrm{g})\end{array}$ \\
\hline TCA & 15 & .2 & 62.9 \\
\hline & & .35 & 12.3 \\
\hline & & .5 & 1.9 \\
\hline & 30 & .10 & 15.5 \\
\hline & & .25 & 6.5 \\
\hline & & .4 & 2.0 \\
\hline & 60 & .1 & 178.6 \\
\hline & & .25 & 42.2 \\
\hline PL4 & & .4 & 4.9 \\
\hline & 15 & .1 & 149.8 \\
\hline & & .25 & ND \\
\hline & 30 & .4 & ND \\
\hline & & .1 & ND \\
\hline & & .4 & $\cdots$ \\
\hline & 60 &.$\cdots$ & ND \\
\hline & & .25 & ND \\
\hline & & .4 & $\cdots$ \\
\hline & & & \multicolumn{2}{c}{} \\
\hline
\end{tabular}

Figure 2: Solvent Depth Profile - GCP

GCP - 90 degrees

\begin{tabular}{|c|c|c|c|}
\hline Solvent & $\begin{array}{c}\text { Time from } \\
\text { Wipe (min) }\end{array}$ & $\begin{array}{c}\text { Depth } \\
(\mathrm{mm})\end{array}$ & $\begin{array}{c}\text { Conc. } \\
(\mu \mathrm{g} / \mathrm{g})\end{array}$ \\
\hline TCA & 15 & .1 & 38 \\
\hline & & .2 & 2 \\
\hline & & .35 & 2 \\
\hline & 30 & .1 & 7 \\
\hline & & .2 & ND \\
\hline & & .3 & ----- \\
\hline & 60 & .1 & ND \\
\hline & & .2 & $-\cdot---$ \\
\hline & & .3 & $-\cdots$ \\
\hline PL4 & 15 & .1 & 15 \\
\hline & & .2 & ND \\
\hline & & .3 & ND \\
\hline & 30 & .1 & ND \\
\hline & & .2 & ND \\
\hline & & .3 & $-\cdots$ \\
\hline & 60 & .1 & 20 \\
\hline & & .2 & 17 \\
\hline & & .3 & 7 \\
\hline
\end{tabular}

GCP - 0 degrees

\begin{tabular}{|c|c|c|c|}
\hline Solvent & $\begin{array}{c}\text { Time from } \\
\text { Wipe (min) }\end{array}$ & $\begin{array}{c}\text { Depth } \\
(\mathrm{mm})\end{array}$ & $\begin{array}{c}\text { Conc. } \\
(\mu \mathrm{g} / \mathrm{g})\end{array}$ \\
\hline TCA & 15 & .1 & 1 \\
\hline & & .25 & .2 \\
\hline & & .4 & .5 \\
\hline & 30 & .15 & 2 \\
\hline & & .3 & .7 \\
\hline & & .45 & ND \\
\hline & 60 & .15 & .6 \\
\hline & & .3 & ND \\
\hline & & .45 & ND \\
\hline PL4 & 15 & .15 & 35 \\
\hline & & .3 & 66 \\
\hline & & .45 & 4 \\
\hline & 30 & .35 & 13 \\
\hline & & .5 & 4 \\
\hline & & .65 & 2 \\
\hline & 60 & .2 & 2 \\
\hline & & .35 & 16 \\
\hline & & .5 & 7 \\
\hline
\end{tabular}


Figure 3: Solvent Depth Profile - SCP

\begin{tabular}{|c|c|c|c|}
\multicolumn{5}{|c}{ SCP - 90 degrees } \\
\hline Solvent & $\begin{array}{c}\text { Time from } \\
\text { Wipe (min) }\end{array}$ & $\begin{array}{c}\text { Depth } \\
(\mathrm{mm})\end{array}$ & $\begin{array}{c}\text { Conc. } \\
(\mu \mathrm{g} / \mathrm{g})\end{array}$ \\
\hline TCA & 15 & .15 & 9 \\
\hline & & .3 & 5 \\
\hline & & .45 & 2 \\
\hline & 30 & .1 & 19 \\
\hline & & .2 & 4 \\
\hline & & .3 & 3 \\
\hline & 60 & .1 & 8 \\
\hline & & .2 & 1 \\
\hline & & .3 & 1 \\
\hline PL4 & 15 & .15 & 1538 \\
\hline & & .25 & 1059 \\
\hline & & .35 & 1454 \\
\hline & 30 & .1 & 794 \\
\hline & & .2 & 1981 \\
\hline & & .3 & 1399 \\
\hline & 60 & .1 & 699 \\
\hline & & .2 & 1147 \\
\hline & & .3 & 1609 \\
\hline
\end{tabular}

Results in Figures 1-3 show that compared to TCA, PL4 is retained in larger concentrations in the first $0.3 \mathrm{~mm}$ of the phenolic surface, even after long dry times. An exception to this is CCP, which, for both $0^{\circ}$ and $90^{\circ}$ ply configurations, showed PL4 concentrations lower than TCA for comparable depths and dry times. For both GCP and SCP, however, PL4 was present in higher concentrations for similar depths and dry times compared to TCA. An extreme example of this behavior was $90^{\circ} \mathrm{SCP}$, which showed PL4 concentrations approximately 1000 times higher than those of TCA for similar depths and dry times.

\section{INTERACTION WITH UNCURED RESIN}

Result from the GCMS-microtome tests showed that, for SCP, and, to a lesser extent, GCP substrates, significant quantities of PL4 remained in the wiped phenolic, even after 60-minute drying times. During full-scale liner fabrication, wet-coat and over-wrap are often conducted within one hour of final solvent wipe, thereby allowing for possible solvent interaction with uncured phenolic resin. Unfortunately, design of a test for solvent effects on uncured phenolic resin was not possible due to difficulties simulating the autoclave or hydroclave cure environments during DSC or dynamic mechanical analysis (DMA). Evaluation of PL4's components as possible cure inhibitors showed that only
SCP - 0 degrees

\begin{tabular}{|c|c|c|c|}
\hline Solvent & $\begin{array}{c}\text { Time from } \\
\text { Wipe (min) }\end{array}$ & $\begin{array}{c}\text { Depth } \\
(\mathrm{mm})\end{array}$ & $\begin{array}{c}\text { Conc. } \\
(\mu \mathrm{g} / \mathrm{g})\end{array}$ \\
\hline TCA & 15 & .1 & 9 \\
\hline & & .2 & 3 \\
\hline & & .3 & 3 \\
\hline & 30 & .1 & 34 \\
\hline & & .2 & 7 \\
\hline & & .3 & 15 \\
\hline & 60 & .1 & 5 \\
\hline & & .2 & 2 \\
\hline & & .3 & 3 \\
\hline PL4 & 15 & .1 & 40 \\
\hline & & .2 & ND \\
\hline & & .3 & $---\cdot$ \\
\hline & 30 & .1 & 21 \\
\hline & & .2 & 7 \\
\hline & & .3 & ND \\
\hline & 60 & .1 & 36 \\
\hline & & .2 & 9 \\
\hline & & .3 & ND \\
\hline
\end{tabular}

one compound, isopropyl myristate, had the potential for interfering with the phenolic cure reaction. Since this component comprises $\approx 5 \%$ of the overall PL4 formulation, it is unlikely to inhibit over-wrap cure sufficiently to affect the strength of the over-wrap interface.

\section{OVER-WRAP BOND TESTS}

Having established PL4's compatibility with cured phenolics and assessed the extent of PL4's retention in both high and low angle CCP, GCP, and SCP, the next step was to evaluate PL4's effect on the strength of the over-wrap interface. Over-wrap interface bond tests were divided into two sets: contaminated and uncontaminanted. With the uncontaminated tests, the goal was to determine whether PL4, in and of itself contributes to lower bond strengths between the cured phenolic and the over-wrap. The uncontaminated bond tests determined whether or not retained PL4 in CCP, GCP or SCP substrates was interfering with cure or creating voids that compromised interfacial strength. Assuming that PL4 performed well in the uncontamined bond tests, the contaminated bond tests would evaluate its ability to remove typical phenolic fabrication area contaminants from over-wrap bond surfaces. Contaminated and uncontaminated test sets used similar test configurations and sample fabrication procedures. 
The phenolic over-wrap bond tests presented two challenges not encountered in adhesive bonding tests. First, since the over-wrap interface and "upper" substrate are formed simultaneously, it was not possible to independently evaluate the interface and the bulk over-wrap phenolic. Second, there were no established test methods or databases available for evaluating phenolic over-wrap bond strength. With no database of test values, it was not possible to determine whether or not results from any given test set represented "characteristic" behavior for the phenolic combination and ply used. This problem was addressed by processing TCA-wiped "control" samples along side the ODC-free samples. For each set of test conditions, tensile adhesion strength values for PL4-treated samples were compared to the TCA control samples from that test set. The acceptability requirement for all bond tests was a mean tensile strength statistically equal to or greater than the TCA control for the test set in question.

\section{SAMPLE FABRICATION AND TESTING}

Over-wrap bond test samples consisted of tensile adhesion disks cored from flat, "over-wrap" test panels fabricated in the laboratory. The panels were formed by "stacking" phenolic pre-preg strips onto a cured, machined, and wet-coated phenolic panel using a starting ramp to achieve the desired ply angle. The stacked panels were autoclave cured using a timetemperature profile designed to simulate full-scale RSRM nozzle liners. Tensile adhesion disks were cored from the cured panels and secondarily bonded to tensile adhesion buttons for testing. All samples were tested at a 0.05 -inch per minute pull rate under ambient conditions.

Solvent wiping, and, where applicable, contamination and cleaning was performed on the machined phenolic panel prior to wet-coat application. Surface cleanliness inspection, was also performed immediately prior to wet-coat application.

Phenolic Combinations and Ply Angles

Over-wrap bond tests were run using the following combinations of machined and over-wrap phenolic materials:

\section{- Machined CCP/ CCP over-wrap}

- Machined CCP/GCP over-wrap

- Machined GCP/CCP over-wrap

- Machined SCP/CCP over-wrap

It was initially assumed that use of steeper ply angles on both machined and over-wrap layers would promote failure at the over-wrap interface by reducing the tendency for interlaminar failure in the bulk phenolics.
Steeper ply angles on the machined (wiped) layer also allowed for greater solvent and contaminant uptake due to the fiber-oriented porosity, thereby increasing the severity of the test from a solvent retention and cleaning standpoint. Uncontaminated bond tests used two different ply angle conditions for each phenolic material combination:

- machined layer steep/over-wrap layer steep

- machined layer shallow/over-wrap layer shallow

In this case, "steep" and "shallow" refer to the ply angle with respect to the wiped interface. Contaminated bond tests used only the "machined layer steep/overwrap layer steep" ply configuration.

\section{UNCONTAMINATED BOND TESTS}

In order to minimize the effects of variation in bulk phenolic tensile strength, the machined (wiped) panels for both TCA and PL4 were cut from blocks of cured CCP, GCP, and SCP. For each unique combination of phenolic type and ply angle, operators fabricated one panel each for PLA and TCA. In order to further reduce effects of bulk phenolic strength, all fabrication processes downstream of solvent wiping, including wetcoat application, over-wrap placement, and cure, were performed simultaneously on the TCA and PL4 panels. Fifteen tensile adhesion disks were cut from each panel. Tables 1 and 2 give mean tensile adhesion strengths (TAS) for steep and shallow ply angles, respectively, along with characteristic failure modes. A legend of characteristic failure modes is given in Figure 4 . It should be noted that the CCP over CCP phenolic combination was only evaluated for shallow ply angles. 
Figure 4: Typical phenolic over-wrap failure modes
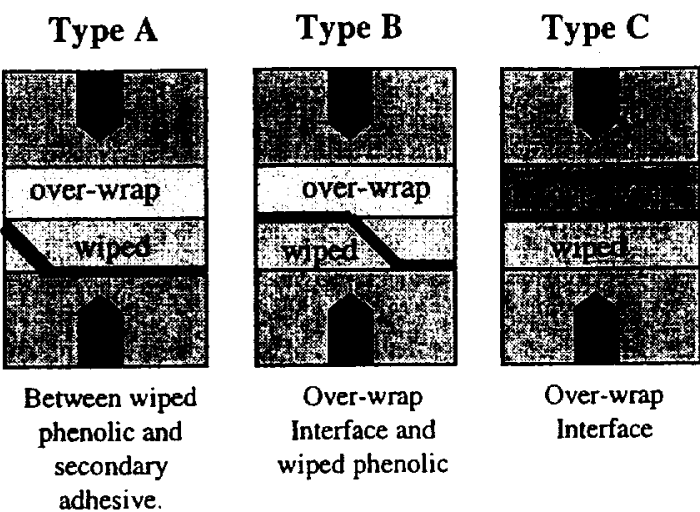

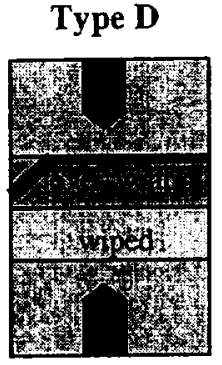

Between overwrap phenolic and secondary adhesive.
Type E

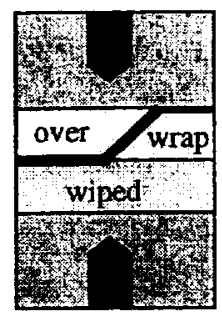

Over-wrap

Interface and

over-wrap

phenolic

Table 1: Mean Tensile Adhesion Strength (psi) and Typical Failure ModeNon-contaminated - Steep Ply Angles

\begin{tabular}{|l|c|c|c|c|c|c|c|c|}
\hline \multirow{2}{*}{ Solvent } & \multicolumn{2}{|c|}{ CCP over SCP } & \multicolumn{2}{l|}{ GCP over CCP } & \multicolumn{2}{l|}{ CCP over GCP } & \multicolumn{2}{l|}{ CCP over CCP } \\
\cline { 2 - 9 } & $\begin{array}{c}\text { TAS } \\
(\% C V)\end{array}$ & $\begin{array}{l}\text { Failure } \\
\text { Mode }\end{array}$ & $\begin{array}{c}\text { TAS } \\
(\% \text { CV })\end{array}$ & $\begin{array}{l}\text { Failure } \\
\text { Mode }\end{array}$ & $\begin{array}{c}\text { TAS } \\
(\% \text { CV })\end{array}$ & $\begin{array}{l}\text { Failure } \\
\text { Mode }\end{array}$ & $\begin{array}{c}\text { TAS } \\
(\% C V)\end{array}$ & $\begin{array}{l}\text { Failure } \\
\text { Mode }\end{array}$ \\
\hline TCA & $2545(15)$ & E & $2681(10)$ & C & $1754(14)$ & D & $\ldots$ & $\ldots \ldots$ \\
\hline PL4 & $2421(13)$ & E & $2509(15)$ & C & $2059(28)$ & D & $\ldots-$ & $\ldots \ldots$ \\
\hline
\end{tabular}

Table 2: Mean Tensile Adhesion Strength (psi) and Typical Failure Mode Non-contaminated - Shallow Ply Angles

\begin{tabular}{|l|c|c|c|c|c|c|c|c|}
\hline \multirow{2}{*}{ Solvent } & \multicolumn{2}{|c|}{ CCP over SCP } & \multicolumn{2}{l|}{ GCP over CCP } & \multicolumn{2}{l|}{ CCP over GCP } & \multicolumn{2}{c|}{ CCP over CCP } \\
\cline { 2 - 9 } & $\begin{array}{c}\text { TAS } \\
(\% \text { CV })\end{array}$ & $\begin{array}{c}\text { Failure } \\
\text { Mode }\end{array}$ & $\begin{array}{c}\text { TAS } \\
(\% C V)\end{array}$ & $\begin{array}{l}\text { Failure } \\
\text { Mode }\end{array}$ & $\begin{array}{c}\text { TAS } \\
(\% \text { CV })\end{array}$ & $\begin{array}{l}\text { Failure } \\
\text { Mode }\end{array}$ & $\begin{array}{c}\text { TAS } \\
(\% \text { CV })\end{array}$ & $\begin{array}{l}\text { Failure } \\
\text { Mode }\end{array}$ \\
\hline TCA & $2632(7)$ & B, E & $1854(8)$ & B & $2172(8)$ & B, E & $1991(17)$ & B,C \\
\hline PL4 & $2522(17)$ & B, E & $1764(14)$ & B & $2276(17)$ & B, E & $1985(10)$ & B,C \\
\hline
\end{tabular}

From the results in Tables 1 and 2, PL4 does not appear to change either tensile adhesion strengths or failure modes for any of the phenolic-ply combinations tested. Statistical analysis (ANOVA, $\alpha=0.05$ ) showed no significant differences in tensile adhesion strengths for PL4 vs. TCA-wiped samples.

Since use of PL4 did not result in reductions in tensile adhesion strength or changes in failure mode for any of the phenolic/ply combinations tested, it was concluded that solvent retained in the wiped layer does not create voids or interfere with resin cure.

\section{CONTAMINATED BOND TESTS}

Tested contaminants included HD-2 grease, Permacel tape, hydraulic oil, and stabilized hydraulic oil, all of which are used on or in close proximity to the phenolic liners during liner fabrication. Sample fabrication procedures for contaminated samples were similar to those used for non-contaminated samples with the exception that a contamination step was added prior to solvent wiping. A single over-wrap panel was fabricated for each independent test condition. Fifteen tensile adhesion buttons were cored from each overwrap panel. Contaminated bond tests were only performed using the steep ply angle configuration as this was considered to be a "worst case" from a contamination absorption standpoint. It was assumed that, if a solvent was capable of removing a contaminant from a steep ply angle phenolic surface, then it should be able to remove that same contaminant form a similar phenolic surface with a more shallow ply angle.

Tables 3-6 give mean tensile adhesion strengths and typical failure modes for each different contaminant. A legend of characteristic failure modes is given in Figure 4. 
Table 3: Mean Tensile Adhesion Strength (psi) and Typical Failure Mode HD-2 Grease Contamination

\begin{tabular}{|l|c|c|c|c|c|c|c|c|}
\hline \multirow{3}{*}{ Solvent } & \multicolumn{2}{|c|}{ CCP over SCP } & \multicolumn{2}{|c|}{ GCP over CCP } & \multicolumn{2}{c|}{ CCP over GCP } & \multicolumn{2}{c|}{ CCP over CCP } \\
\cline { 2 - 9 } & $\begin{array}{c}\text { TAS } \\
(\% \text { CV })\end{array}$ & $\begin{array}{c}\text { Failure } \\
\text { Mode }\end{array}$ & $\begin{array}{c}\text { TAS } \\
(\% \mathrm{CV})\end{array}$ & $\begin{array}{l}\text { Failure } \\
\text { Mode }\end{array}$ & $\begin{array}{c}\text { TAS } \\
(\% \mathrm{CV})\end{array}$ & $\begin{array}{l}\text { Failure } \\
\text { Mode }\end{array}$ & $\begin{array}{c}\text { TAS } \\
(\% \mathrm{CV})\end{array}$ & $\begin{array}{l}\text { Failure } \\
\text { Mode }\end{array}$ \\
\hline TCA & $3589(14)$ & $\mathrm{E}$ & $2594(19)$ & $\mathrm{C}$ & $1604(16)$ & D,E & $3280(8)$ & E \\
\hline PL4 & $3864(10)$ & E & $2774(19)$ & $\mathrm{C}$ & $1730(16)$ & D,E & $3098(12)$ & E \\
\hline
\end{tabular}

Table 4: Mean Tensile Adheison Stength (psi) and Typical Failure Mode Permacel Tape Contaminant

\begin{tabular}{|l|c|c|c|c|c|c|c|c|}
\hline \multirow{3}{*}{ Solvent } & \multicolumn{2}{|c|}{ CCP over SCP } & \multicolumn{2}{c|}{ GCP over CCP } & \multicolumn{2}{l|}{ CCP over GCP } & \multicolumn{2}{c|}{ CCP over CCP } \\
\cline { 2 - 9 } & $\begin{array}{c}\text { TAS } \\
(\% \mathrm{CV})\end{array}$ & $\begin{array}{c}\text { Failure } \\
\text { Mode }\end{array}$ & $\begin{array}{c}\text { TAS } \\
(\% \mathrm{CV})\end{array}$ & $\begin{array}{l}\text { Failure } \\
\text { Mode }\end{array}$ & $\begin{array}{c}\text { TAS } \\
(\% \mathrm{CV})\end{array}$ & $\begin{array}{l}\text { Failure } \\
\text { Mode }\end{array}$ & $\begin{array}{c}\text { TAS } \\
(\% \mathrm{CV})\end{array}$ & $\begin{array}{l}\text { Failure } \\
\text { Mode }\end{array}$ \\
\hline TCA & $3709(13)$ & D,E & $3110(19)$ & $\mathrm{E}$ & $1715(12)$ & $\mathrm{D}$ & $3614(15)$ & E \\
\hline PL4 & $4174(10)$ & D,E & $3364(13)$ & E & $2006(18)$ & D,E & $3108(11)$ & E \\
\hline
\end{tabular}

Table 5: Mean Tensile Adhesion Strength (psi) and Typical Failure Mode Hydraulic Oil Contaminant

\begin{tabular}{|l|c|c|c|c|c|c|c|c|}
\hline \multirow{3}{*}{ Solvent } & \multicolumn{2}{|c|}{ CCP over SCP } & \multicolumn{2}{l|}{ GCP over CCP } & \multicolumn{2}{l|}{ CCP over GCP } & \multicolumn{2}{c|}{ CCP over CCP } \\
\cline { 2 - 9 } & $\begin{array}{c}\text { TAS } \\
(\% C V)\end{array}$ & $\begin{array}{c}\text { Failure } \\
\text { Mode }\end{array}$ & $\begin{array}{c}\text { TAS } \\
(\% \text { CV })\end{array}$ & $\begin{array}{l}\text { Failure } \\
\text { Mode }\end{array}$ & $\begin{array}{c}\text { TAS } \\
(\% \text { CV })\end{array}$ & $\begin{array}{l}\text { Failure } \\
\text { Mode }\end{array}$ & $\begin{array}{c}\text { TAS } \\
(\% C V)\end{array}$ & $\begin{array}{l}\text { Failure } \\
\text { Mode }\end{array}$ \\
\hline TCA & $3537(11)$ & D,E & $3108(16)$ & C & $1873(9)$ & D,E & $3756(13)$ & E \\
\hline PLA & $3488(13)$ & D,E & $3333(12)$ & C & $1792(10)$ & D,E & $3316(14)$ & E \\
\hline
\end{tabular}

Table 6: Mean Tensile Adhesion Strength (psi) and Typical Failure Mode Stabilized Hydraulic Oil Contaminant

\begin{tabular}{|l|c|c|c|c|c|c|c|c|}
\hline \multirow{3}{*}{ Solvent } & \multicolumn{2}{|c|}{ CCP over SCP } & \multicolumn{2}{|c|}{ GCP over CCP } & \multicolumn{2}{c|}{ CCP over GCP } & \multicolumn{2}{c|}{ CCP over CCP } \\
\cline { 2 - 9 } & $\begin{array}{c}\text { TAS } \\
(\% \text { CV })\end{array}$ & $\begin{array}{c}\text { Failure } \\
\text { Mode }\end{array}$ & $\begin{array}{c}\text { TAS } \\
(\% \text { CV })\end{array}$ & $\begin{array}{l}\text { Failure } \\
\text { Mode }\end{array}$ & $\begin{array}{c}\text { TAS } \\
(\% \text { CV })\end{array}$ & $\begin{array}{l}\text { Failure } \\
\text { Mode }\end{array}$ & $\begin{array}{c}\text { TAS } \\
(\% \text { CV })\end{array}$ & $\begin{array}{l}\text { Failure } \\
\text { Mode }\end{array}$ \\
\hline TCA & $3969(11)$ & E & $3443(10)$ & C & $1401(30)$ & D & $3520(14)$ & C \\
\hline PL4 & $3844(9)$ & E & $2502(20)$ & C & $1753(12)$ & D & $3694(10)$ & C,E \\
\hline
\end{tabular}

Statistical analysis (ANOVA, $\alpha=0.05$ ) comparing the effects of solvents in tensile adhesion strengths for PL4 vs. TCA-wiped samples showed the following:

- HD-2 Grease - no significant differences for any phenolic combination.

- Permacel Tape - CCP over SCP and GCP over CCP: no significant differences. CCP over CCP: PL4<TCA. CCP over GCP: PL4>TCA.
- Hydraulic Oil - no significant differences for any phenolic combination.

- Stabilized Hydraulic Oil - CCP over SCP and CCP over CCP: no significant differences. CCP over GCP: PL4>TCA. GCP over CCP: PL4<TCA.

The data in Tables 3-6 and the statistical analysis results for permacel tape and stabilized hydraulic oil contaminant raise several issues: 
- PL4 appeared to perform as well as TCA for Permacel tape removal from CCP in the GCP over CCP test set, but did not perform as well as TCA in removing Permacel tape from a similar CCP panel in the CCP over CCP test set. Failure modes were similar in all cases.

- The high \%CV for the TCA-wiped, stabilized hydraulic oil contaminated CCP over GCP test set is inconsistent with those for other test sets.

- The low tensile adhesion strength for the TCAwiped, stabilized hydraulic oil contaminated CCP over GCP test is inconsistent with its predominantly cohesive failure mode.

These issues prompted a review of sample fabrication and testing methods used for the contaminated overwrap bond tests. This review identified several fabrication and test procedures that were thought to have contributed to the issues listed above:

- The tensile adhesion buttons used for the test were an older, "anvil-style" button that is fixtured into the test machine using a set of yokes. This "yoke and anvil" fixturing system can result in off-axis loading of the samples during testing, the magnitude of which can vary from test to test. Due to the stiffness and anisotropy of the phenolic samples, this offaxis loading can dramatically alter the measured tensile adhesion strength and failure modes.

- Due to diameter mismatch between phenolic disks and tensile adhesion buttons, several samples had a small ( $\approx 8 \mathrm{mil}$ ) "step" between the phenolic disk and tensile adhesion buttons. These "steps" formed stress-risers at the secondary bondlines and are thought to have contributed to higher incidences of failure initiation between phenolic disks and secondary adhesive.

- The visual and black light inspection methods used to assess sample cleanliness after solvent wiping did not represent current production practices. In full-scale production, FourierTransform Infra-red Spectroscopy (FTIR) analysis is used to assess the cleanliness of a surface after contamination removal. FTIR is a much more rigorous inspection technique than either visible or black light.
- The steep ply angle configuration was thought to be an severe test of solvent cleaning performance as the ply angles relative to the wiped interface were much steeper than those used in any production liners.

\section{OVER-WRAP BOND RECOVERY TESTS}

In order to address the issues raised above, a second set of contaminated over-wrap bond test were run using the following modifications to sample fabrication and test procedures:

- A new, "screw-back" style of tensile adhesion buttons was substituted for the anvil style tensile adhesion buttons. This screw-back button is less susceptible to off-axis loading than the anvil-style button.

- The mismatch between phenolic disks and tensile adhesion buttons was eliminated.

- FTIR inspection procedures were used to assess cleanliness after solvent cleaning.

- The steep ply angle configuration relative to the wiped interface was changed to a "moderate", albeit still "conservative" ply angle, which was more representative of production parts.

Since this recovery test is considered to be generally less severe from the standpoint of solvent qualification, testing was restricted to contaminants and phenolic combinations for which PLA had shown statistically lower tensile adhesion strengths relative to TCA, or for which data appeared to have been questionable on the initial test set. The recovery tests included the following contaminant/phenolic combinations:

- CCP over CCP - permacel tape and hydraulic oil contaminants

- CCP over GCP - all contaminants

- GCP over CCP - hydraulic oil and stabilized hydraulic oil contaminants.

At this time, results are available only for the hydraulic oil and stabilized hydraulic oil contaminants on CCP over GCP and GCP over CCP phenolic combinations. These results are shown in Tables 7 and 8 . 
Table 7: Mean Tensile Adhesion Strength and Typical Failure Mode Hydraulic Oil Recovery Tests

\begin{tabular}{|l|c|c|c|c|}
\hline \multirow{3}{*}{ Solvent } & \multicolumn{2}{|c|}{ GCP over CCP } & \multicolumn{2}{c|}{ CCP over GCP } \\
\cline { 2 - 5 } & $\begin{array}{c}\text { TAS } \\
(\% \mathrm{CV})\end{array}$ & $\begin{array}{l}\text { Failure } \\
\text { Mode }\end{array}$ & $\begin{array}{c}\text { TAS } \\
(\% \mathrm{CV})\end{array}$ & $\begin{array}{l}\text { Failure } \\
\text { Mode }\end{array}$ \\
\hline TCA & $3527(8)$ & $\mathrm{E}$ & $2135(16)$ & $\mathrm{E}$ \\
\hline PL4 & $3468(12)$ & $\mathrm{E}$ & $2149(17)$ & $\mathrm{E}$ \\
\hline
\end{tabular}

Table 8: Mean Tensile Adhesion Strength and Typical Failure Mode Stabilized Hydraulic Oil Recovery Tests

\begin{tabular}{|l|c|c|c|c|}
\hline \multirow{2}{*}{ Solvent } & \multicolumn{2}{|c|}{ GCP over CCP } & \multicolumn{2}{c|}{ CCP over GCP } \\
\cline { 2 - 5 } & $\begin{array}{c}\text { TAS } \\
(\% \mathrm{CV})\end{array}$ & $\begin{array}{l}\text { Failure } \\
\text { Mode }\end{array}$ & $\begin{array}{c}\text { TAS } \\
(\% \mathrm{CV})\end{array}$ & $\begin{array}{l}\text { Failure } \\
\text { Mode }\end{array}$ \\
\hline TCA & $2578(15)$ & $\mathrm{C}$ & $2452(10)$ & D,E \\
\hline PL4 & $3169(12)$ & $\mathrm{C}$ & $2147(19)$ & D,E \\
\hline
\end{tabular}

Statistical analysis (ANOVA, $\alpha=0.05$ ) comparing the effects of solvents in tensile adhesion strengths for PL4 vs. TCA-wiping for test configurations in Tables 7 and 8 showed the following:

- Hydraulic Oil contamination - CCP over GCP and GCP over CCP: no significant differences

- Stabilized hydraulic oil contamination - CCP over GCP: no significant differences, GCP over CCP: PL4>TCA.

\section{CONCLUSIONS}

Based on the testing performed to date, the following conclusions can be made about suitability of PL4 solvent as a TCA replacement for phenolic fabrication operations:

- PLA is compatible with cure carbon, glass, and silica cloth phenolics.

- PLA tends to be retained in the surfaces of machined silica cloth and glass cloth phenolic in higher concentrations than TCA for similar wiping operations. This is especially true of silica cloth phenolics with steep ply angles relative to the wiped surface.

- Despite its higher retained concentrations, PL4 does not contribute to lowered tensile adhesion strengths of phenolic over-wrap bonds for either steep or shallow ply angles.
- PL4 appears to be effective for removing commonly encountered contaminants from machined phenolic surfaces in preparation for over-wrap. 